\title{
Analyzing the Impact of the Internet on Higher Education
}

\author{
Renjie Zhou ${ }^{1, *}$, Dongchen $\mathrm{Xia}^{1}$, Yuyu Yin ${ }^{1}$, Jilin Zhang ${ }^{1}$, Wei Zhang ${ }^{1}$ and Jin \\ Feng $^{2}$ \\ ${ }^{1}$ School of Computer Science and Technology, Hangzhou Dianzi University, \\ Hangzhou, China. \\ ${ }^{1}$ Key Laboratory of Complex Systems Modeling and Simulation, Ministry of \\ Education, Hangzhou, China. \\ ${ }^{2}$ PLA the Rocket Force Command College, Wuhan 430012, China \\ "rjzhou@hdu.edu.cn
}

\begin{abstract}
The Internet has gone deeply into nowadays college students' life, and has become an important platform for students to study, entertainment, and build social relationships. In this paper, we study the patterns of how college students use the Internet, and analyze the potential impacts of Internet on the living and education of college students. We find that 95\% of college students spend more than two hours online per day. Academic and career development is the top motivation for college students to use the Internet. However, high percentage of the college students is not able to control their usage of the Internet well, which leading to recognition that the Internet is a negative factor that affects their course performance. The findings are helpful for educators to guide students to use Internet in a reasonable way and to find ways to make the Internet to be conducive to high quality of higher education.
\end{abstract}

Keywords: Internet usage pattern, online learning resources, higher education, impact

\section{Introduction}

The rapid development of the Internet technologies has greatly affected all areas of the society. The college students exhibit a high degree of enthusiasm for participating in the virtual world built by the Internet. As the growing popularity of personal computers and smart phones, the Internet has gone deep into today's college students' life, and has become an important platform for students to study, entertainment, and build social relationships. More and more people agree that higher education is undergoing rapid change [1], universities are facing the biggest challenge in 800 years [2]. Because of the Internet, the digital world is changing almost all human activities [3], it is expected that higher education will also experience great social upheaval like music and newspapers [4].

In 2009, England Higher Education Funding Council set up an online learning research group. The group found that online learning enables UK universities to develop a truly massive, cost-effective education that can be met at home and abroad. In 2010, it is estimated that 17 million students learned through distance learning institutions around the world [5]. Recently, massive open online course (MOOC) has quickly become one of the hottest topics in higher education [6]. For example, the EDX founded by Harvard University has more than 40 million students. In addition, there are more than 200 million students enrolled in curriculums of world's 50 most famous universities provided by Coursea [7].

\footnotetext{
* Renjie Zhou and Dongchen Xia are co-first authors who contribute to this work equally. Renjie Zhou is the corresponding author.
} 
On the other hand, many people browse somewhat intoxicated and always feel time flies when they are surfing the Internet. However, from the view of learning, they end up learning nothing after closing the browser. This is because the network is likely to encourage learners to learn shallow learning [8]. Excessive use of and reliance on the Internet may be harmful for College Students' physical and mental health [9]. More and more college students are experiencing excessive dependence on the Internet; some of them are even addict to the Internet, which will cause great negative impact on their development [10].

Therefore, it is necessary to study how the college students are involved in the Internet world, and to know how they recognize the impact of Internet technologies on their education and career development. In this paper, we conduct an online survey of the college students through a web-based survey platform. The findings are helpful for educators to guide students to use Internet in a reasonable way and to find ways to make the Internet to be conducive to successful learning.

The rest of the paper is organized as follows. In Section 2, we introduce the methodology adopted in the paper. In Section 3, we present the results of our study and provide the discussions of the results. Finally, we conclude the paper in Section 4.

\section{Methodology}

For research methods, this paper adopts empirical research method and strives to achieve a comprehensive combination of qualitative analysis and quantitative research. As a research paradigm, empirical research advocates for employing the empirical natural science spirit to carry out the study of social phenomena. Through analyzing a large number of observations, experiments and surveys, empirical research aims to obtain the deep understanding of the inherent law of social phenomena. The methods of empirical research include the observation method, interview method and the questionnaire method.

In this paper, we take the questionnaire method to obtain the objective and credible first-hand information. The questionnaire was conducted on an online platform. There are totally 19 questions in the questionnaire and there are four types of questions including single choice, multiple choices, ranking and fill-in-the-blanks. The students were invited to attend the survey via email, QQ, Wechat messages. In order to prevent people who are not college students answering the questionnaire, we put a highlighted caution on the top of the questionnaire and design a question that requires the participants to answer in which grade they are. The participants of the survey are voluntary and anonymous. After obtaining the data from the questionnaire, we conduct a comprehensive quantitative analysis of the data. The results and analysis are presented in the next section.

\section{Results and Discussion}

There were totally 192 students participating in the survey. The respondents were from more than ten different provinces of China. Among the respondents, $44.7 \%$ are male and $55.3 \%$ are female. The grade distribution of the respondents is that $25 \%$ are freshmen, $47.4 \%$ are sophomore, $2.6 \%$ are junior, $5.8 \%$ are senior and $9.2 \%$ are postgraduates.

We now investigate how many hours college students spend online each day. As can be seen from Figure 1, none of the respondents reported that they spent less than one hour online per day. Approximately $4.0 \%$ of the respondents reported that they spent one to two hours online per day. $43.4 \%$ of the respondents claimed two to four hours online per day; $31.6 \%$ said four to eight hours online per day and $20.0 \%$ said more than eight hours online per day. In summary, more than $95 \%$ of repliers reported that they spent more than two hours online per day.

When the respondents were asked to report whether the length of time spending online is reasonable, $31.6 \%$ of them claimed they spent reasonable amount of time online per day. Only less than $3 \%$ of them regarded that they spent too less time online. The 
percentage of students who considered they spent a little bit longer than reasonable is $47.37 \%$, and the percentage of students who regarded they spent extremely too much time on the Internet is $18.42 \%$. From this question, we can see that about two thirds of students reported that they had better to limit the amount of time spending on the Internet.

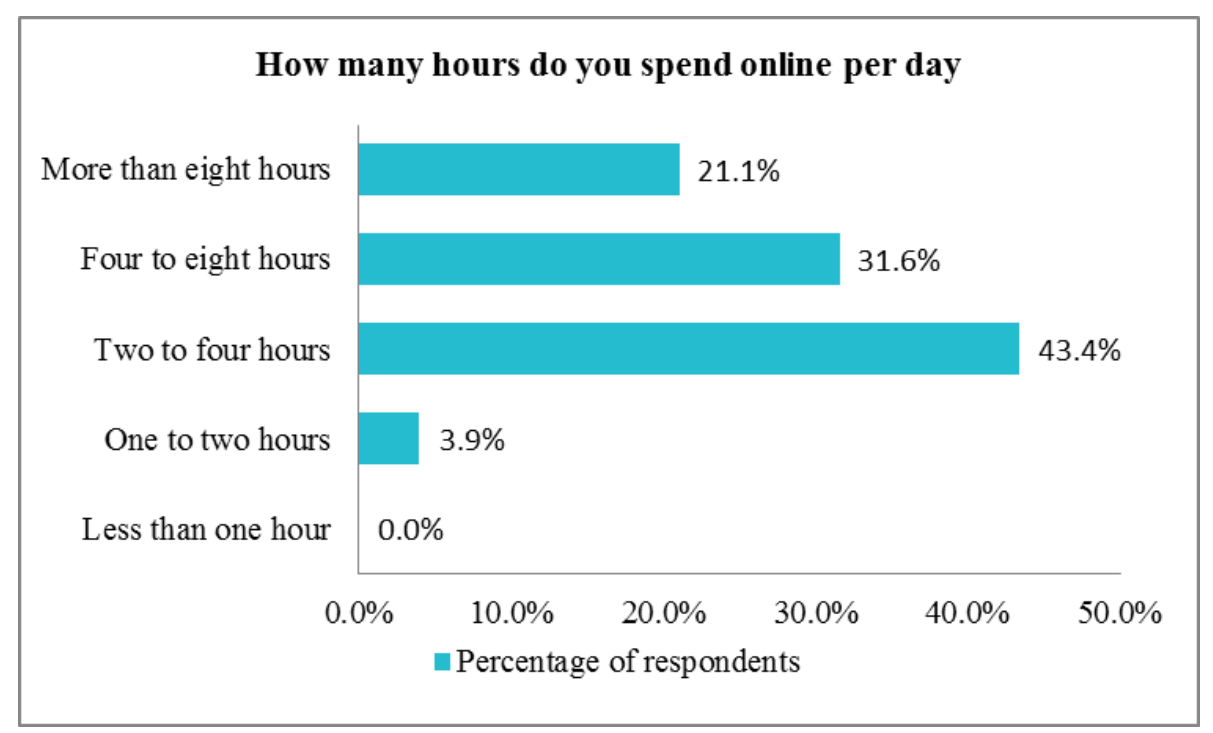

Figure 1. How Many Hours do you spend Online per Day

The respondents were asked whether they think the impact of the Internet on the course performance is positive or negative. 57.9\% of the respondents considered that the Internet generated a general negative impact on their academic performance and approximately $34.2 \%$ of the respondents regarded the Internet as a positive factor for their academic performance and $7.9 \%$ of the students thought that the Internet was neutral factor. From this question, it is found that more than half of the respondents thought the Internet hindered their achievement in course performance.

Next, we investigate in which aspects the students spend their time. We list six choices, which are academic and career development; living affairs; news and society concerns; entertainment; amateur hobbies; social contact. The respondents were asked to rank the choices according to the amount of time they spend. As shown in Table 1, the first column is the six choices and the second column is the percentage of respondents who ranked the corresponding choice as the first position of the list. The rest of the columns are similar as the second column. The summation of each row and each column is $100 \%$. As can be seen from the table, $46.1 \%$ of the respondents ranked the entertainment in the first place, which means nearly half of the respondents spent more time in entertainment than in other aspects. The percentage of the respondents spent the longest time in academic and career development among all of the aspects is 25\%. Approximately, $61.8 \%$ of the respondents spent the least of time in news and society concerns. In order to present a more intuitive importance of all the aspects, we compute the weighted rank (WR) for each choice.

$r_{w}(c)=\sum_{r=1}^{n} r(c) \cdot p_{r}(c)$

Where $r_{w}(c)$ represents the weighted rank for each choice, $c$ represents a choice, $n$ represents the number of choices, $r(c)$ indicates the rank of choice $c, p_{r}(c)$ represents the percentage of respondents ranked the choice $c$ in position $r(c)$. 
Table 1. The Ranking of Aspects on which Respondents Spend Time

\begin{tabular}{|l|c|c|c|c|c|c|c|}
\hline \multicolumn{1}{|c|}{ Choices } & R1 & R2 & R3 & R4 & R5 & R6 & WR \\
\hline $\begin{array}{l}\text { academic and career } \\
\text { development }\end{array}$ & $25.0 \%$ & 22.4 & $23.7 \%$ & $15.8 \%$ & $9.2 \%$ & $4.0 \%$ & 2.7 \\
\hline living affairs & $5.3 \%$ & $18.4 \%$ & $9.2 \%$ & $25.0 \%$ & $36.8 \%$ & $5.3 \%$ & 3.9 \\
\hline $\begin{array}{l}\text { news and society } \\
\text { concerns }\end{array}$ & $4.0 \%$ & $2.6 \%$ & $13.2 \%$ & $7.9 \%$ & $10.5 \%$ & $61.8 \%$ & 5.0 \\
\hline entertainment & $46.1 \%$ & $19.7 \%$ & $9.2 \%$ & $14.5 \%$ & $5.3 \%$ & $5.3 \%$ & 2.3 \\
\hline amateur hobbies & $14.5 \%$ & $22.4 \%$ & $29.0 \%$ & $11.8 \%$ & $18.4 \%$ & $4.0 \%$ & 3.1 \\
\hline social contact & $5.3 \%$ & $14.5 \%$ & $15.8 \%$ & $25.0 \%$ & $19.7 \%$ & $19.7 \%$ & 4.0 \\
\hline
\end{tabular}

Next, we investigate on which network-based application (App) students spent their time. We list eleven choices, which are QQ, Wechat (WT), weibo (WO), blog (BG), search engine (SE), multimedia websites (MW), online gaming (OG), news website (NW), forum (FM), online social networking $(\mathrm{ON})$, and academic resources websites (AW). QQ is the most popular instant messenger application in China, with more than one billion of registered users and two hundred million users online at the same time. The QQ application can be used in computers and smart terminals. WeChat, which is the English version of Weixin, is the hottest smart phone instant messenger and social networking application launched in 2011 by Tecent. According to the statistics, Wechat has more than seven hundred million registered users around the world. Weibo is microblogging application, which is the China's counterpart of Twitter. The respondents were asked to rank the applications according to the amount of time they spend on them. As shown in Table 2, QQ is the most heavily used application, about $41 \%$ of the participants ranked QQ as the top application among all of the candidate applications. The second most heavily used application is Multimedia websites, $14 \%$ of respondents spent the longest time on this kind of application. Unfortunately, only $4 \%$ of respondents used academic resources most heavily. In the weighted ranking scenario, QQ, Multimedia websites, Wechat are the top three most intensively used applications and the blog, digital forum and news websites are the bottom three applications in terms of length of time spending on them.

Table 2. The Ranking of Applications on which Respondents Spend Time

\begin{tabular}{|l|c|c|c|c|c|c|c|c|c|c|c|c|}
\hline App & R1 & R2 & R3 & R4 & R5 & R6 & R7 & R8 & R9 & R10 & R11 & WR \\
\hline QQ & $41 \%$ & $17 \%$ & $18 \%$ & $11 \%$ & $4 \%$ & $3 \%$ & $1 \%$ & $1 \%$ & $3 \%$ & $0 \%$ & $1 \%$ & 2.7 \\
\hline WT & $12 \%$ & $30 \%$ & $12 \%$ & $8 \%$ & $7 \%$ & $5 \%$ & $11 \%$ & $3 \%$ & $7 \%$ & $4 \%$ & $3 \%$ & 4.3 \\
\hline WO & $12 \%$ & $11 \%$ & $28 \%$ & $5 \%$ & $9 \%$ & $9 \%$ & $5 \%$ & $5 \%$ & $1 \%$ & $9 \%$ & $5 \%$ & 4.8 \\
\hline BG & $1 \%$ & $1 \%$ & $0 \%$ & $9 \%$ & $9 \%$ & $7 \%$ & $4 \%$ & $13 \%$ & $18 \%$ & $16 \%$ & $21 \%$ & 8.1 \\
\hline SE & $8 \%$ & $9 \%$ & $14 \%$ & $14 \%$ & $17 \%$ & $18 \%$ & $9 \%$ & $3 \%$ & $4 \%$ & $3 \%$ & $0 \%$ & 4.7 \\
\hline MW & $14 \%$ & $18 \%$ & $12 \%$ & $13 \%$ & $13 \%$ & $9 \%$ & $8 \%$ & $7 \%$ & $3 \%$ & $3 \%$ & $0 \%$ & 4.2 \\
\hline OG & $3 \%$ & $7 \%$ & $7 \%$ & $8 \%$ & $3 \%$ & $7 \%$ & $13 \%$ & $9 \%$ & $9 \%$ & $11 \%$ & $25 \%$ & 7.5 \\
\hline NW & $3 \%$ & $0 \%$ & $1 \%$ & $8 \%$ & $9 \%$ & $5 \%$ & $11 \%$ & $18 \%$ & $17 \%$ & $20 \%$ & $8 \%$ & 7.8 \\
\hline FM & $1 \%$ & $3 \%$ & $1 \%$ & $4 \%$ & $5 \%$ & $1 \%$ & $14 \%$ & $20 \%$ & $20 \%$ & $17 \%$ & $13 \%$ & 8.1 \\
\hline ON & $1 \%$ & $1 \%$ & $3 \%$ & $7 \%$ & $9 \%$ & $13 \%$ & $13 \%$ & $14 \%$ & $13 \%$ & $12 \%$ & $13 \%$ & 7.5 \\
\hline AW & $4 \%$ & $3 \%$ & $4 \%$ & $13 \%$ & $14 \%$ & $22 \%$ & $11 \%$ & $7 \%$ & $5 \%$ & $7 \%$ & $11 \%$ & 6.4 \\
\hline
\end{tabular}

The next question is about whether college students used the Internet during a class that does not require usage of the Internet. From the Table 3, half of students reported that 
they surfed the Internet sometimes. $18.4 \%$ of students presented the viewpoint that they often accessed the Internet. Meanwhile, $13.2 \%$ of the students reported that they surfed the Internet more than 10 minutes in each class on average. However, only $6.6 \%$ of students did not surf the Internet. In a word, more than $90 \%$ of students reported that they surfed the Internet during the course even though the class can be taken without the Internet.

Table 3. Surf the Internet during the Course

\begin{tabular}{|l|l|}
\hline Choices & Percentage \\
\hline Never & $6.6 \%$ \\
\hline Rarely & $11.8 \%$ \\
\hline Sometimes & $50.0 \%$ \\
\hline Often & $18.4 \%$ \\
\hline More than 10 minutes & $13.2 \%$ \\
\hline
\end{tabular}

We examine the attitude about the topic that students in the classroom are forbidden to surf the Internet for classes that can be taken without the Internet. Surprisingly, as shown in Table 4, 40.8\% of the respondents claimed that they would oppose the rule, $38.2 \%$ of the respondents would maintain a neutral view, while the number of students who reported that they would support the rule accounts for only $21 \%$ of the respondents.

Table 4. The Attitude about being Forbidden to Surf the Internet

\begin{tabular}{|l|l|}
\hline Choices & Percentage \\
\hline Strong opposite & $15.8 \%$ \\
\hline Opposite & $25.0 \%$ \\
\hline Neutral & $38.2 \%$ \\
\hline Supportive & $18.4 \%$ \\
\hline Strongly supportive & $2.6 \%$ \\
\hline
\end{tabular}

The respondents were asked whether teacher employed the Internet to support the course in the classroom. From the Table 5, nearly half of the respondents said it would sometimes be used, often used in close to $30 \%$. It is can be seen that the network does not only affect the students, but also influences the teacher's teaching methods.

Table 5. Whether Teachers use the Internet to Help to Teach the Course

\begin{tabular}{|l|l|}
\hline Choices & Percentage \\
\hline Never & $0.0 \%$ \\
\hline Rarely & $17.1 \%$ \\
\hline Sometimes & $48.7 \%$ \\
\hline Often & $27.6 \%$ \\
\hline More than 10 minutes & $6.6 \%$ \\
\hline
\end{tabular}

Furthermore, when the respondents were asked whether the teacher applied the Internet to help the students after class. From the Table 6, 19.7\% often used, more than 50\% explained that sometimes used. In summary, it is found that the network was an important assistive tool for teachers to guide students.

Table 6. Whether Teachers use the Internet to Help Students after Class

\begin{tabular}{|l|l|}
\hline Choices & Percentage \\
\hline Never & $0.0 \%$ \\
\hline
\end{tabular}




\begin{tabular}{|l|l|}
\hline Rarely & $21.1 \%$ \\
\hline Sometimes & $53.9 \%$ \\
\hline Often & $19.7 \%$ \\
\hline More than 10 minutes & $5.3 \%$ \\
\hline
\end{tabular}

Next, we investigate the type of frequently used network learning resources. We list seven choices, which are MOOC websites, traditional online videos, online PPT, academic paper, professional forum, blog, study group. From the Figure 2, we can see online PPT and some network communities occupy the proportion, network videos, academic journals also occupy a ratio more than $30 \%$, the study group occupies the smallest percentage, only $21.1 \%$.

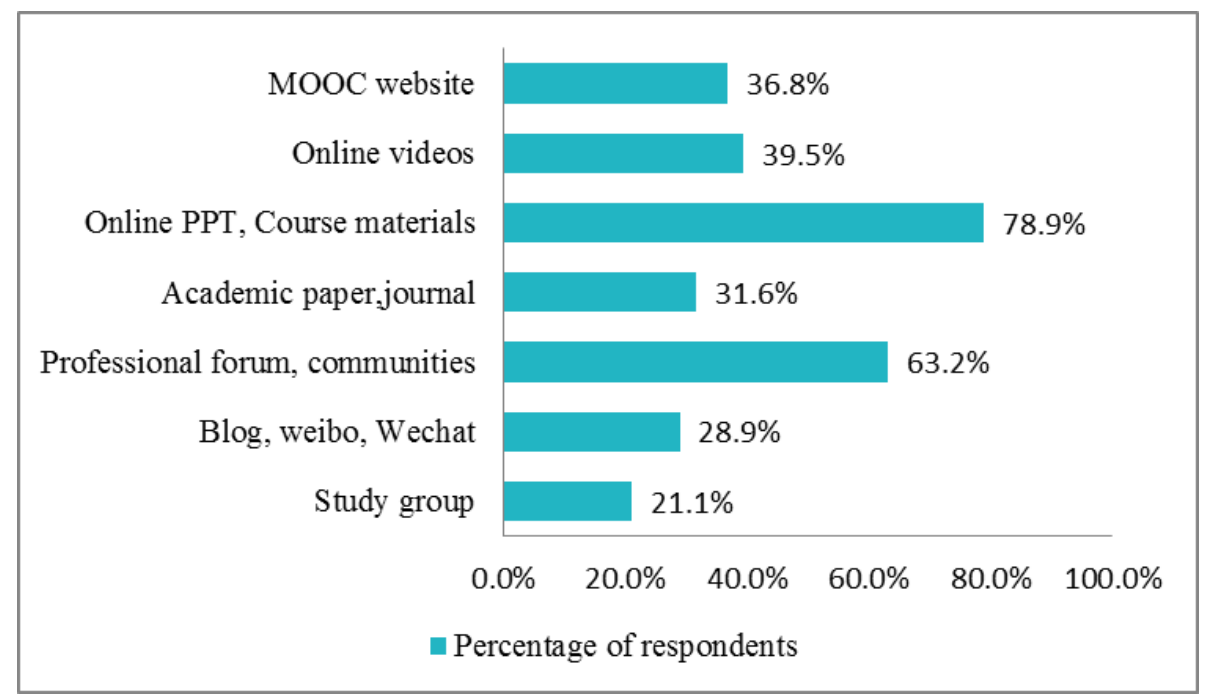

Figure 2. Which Network Learning Resource you will Choose

When the respondents were asked the attitude about the online learning resources. As presented in the Table 7, nearly $90 \%$ maintained a positive attitude and no one in the survey considered online learning resources unimportant. Obviously, the vast majority of the respondents reported that the network learning resources was important.

Table 7. The Attitude about the Learning Resources

\begin{tabular}{|l|l|}
\hline Choices & Percentage \\
\hline Very important & $38.2 \%$ \\
\hline Important & $50.0 \%$ \\
\hline Moderate & $11.8 \%$ \\
\hline Little important & $0.0 \%$ \\
\hline Nearly useless & $0.0 \%$ \\
\hline
\end{tabular}

The respondents were asked whether they had a high efficiency in studying using online learning resources. It is can be seen from Table 8 , more than half of them believed that the study of online learning resources yielded a high efficiency, $44.7 \%$ of them reported that the efficiency of studying using network resources is moderate, only $3.9 \%$ of them think that the efficiency is low in digesting network learning resources. Hence, we can say that the network learning resource are advantages to the students in general.

Table 8. The Study Efficiency using the Network Learning Resources 


\begin{tabular}{|l|l|}
\hline Choices & Percentage \\
\hline Very high & $9.2 \%$ \\
\hline High & $42.1 \%$ \\
\hline Moderate & $44.7 \%$ \\
\hline Low & $1.3 \%$ \\
\hline Very low & $2.6 \%$ \\
\hline
\end{tabular}

Moreover, we investigated the students' confidence in the network learning resources. From the Table $9,60.5 \%$ of the students rated high credibility to the network learning resources, $38.2 \%$ of the students reported that they believed the general, while only $1.3 \%$ of the students regarded that the network resources were with low credibility. Here we can summarize that the network is not only rich but also has quite high quality in learning resources.

Table 9. The Credibility of the Network Resources

\begin{tabular}{|l|l|}
\hline Choices & Percentage \\
\hline Very high & $10.5 \%$ \\
\hline High & $50.0 \%$ \\
\hline Moderate & $38.2 \%$ \\
\hline Low & $0.0 \%$ \\
\hline Very low & $1.3 \%$ \\
\hline
\end{tabular}

The next question is about whether they would be distracted by unrelated online resources during the process of learning materials in the Internet. As shown in the Figure 3 , the majority of the students were quite concentrated in the online learning, but $40.8 \%$ of the students reported that they would chat with others when learning the knowledge, and $11.8 \%$ of the students played games unconsciously, $27.6 \%$ of the students would browse to the uncorrelated websites. Here we find that some students are lack of selfcontrol capability and are easy to be distracted by other online factors during the process of online learning.

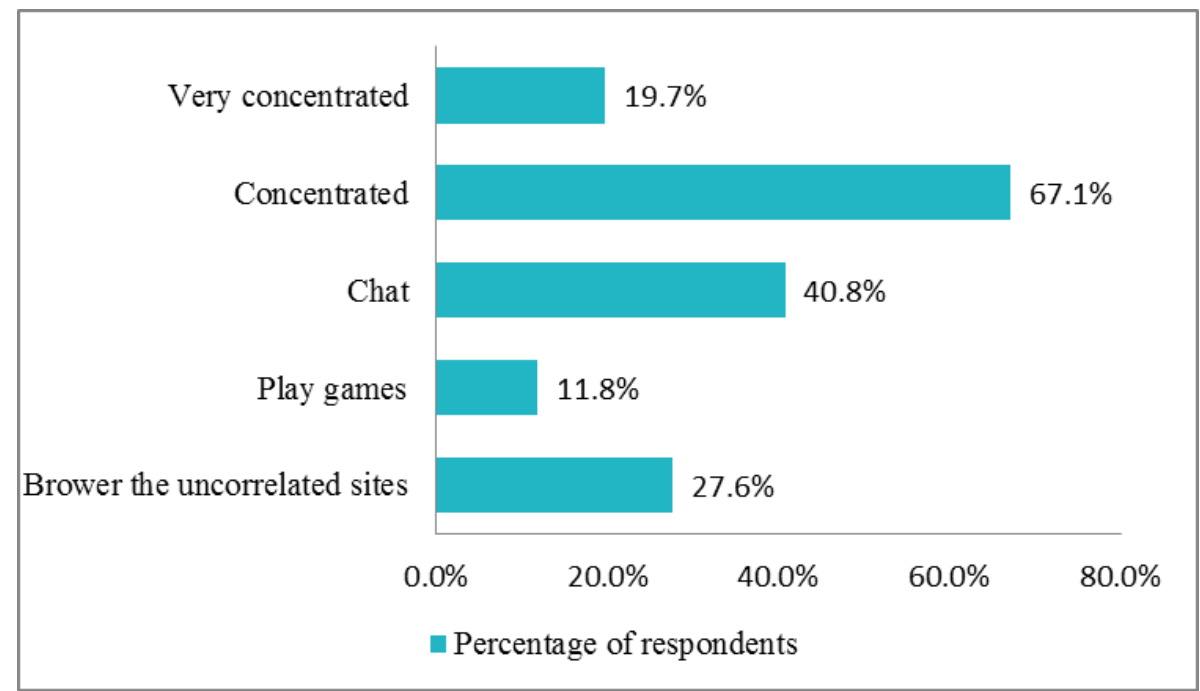

Figure 3. The Study Condition when you Learn the Network Resources 


\section{Conclusions}

In this paper, we study the patterns of how college students use the Internet, and analyze the impacts of the Internet on the living and academic performance of college students. We find that $95 \%$ of college students spend more than two hours online per day. Two thirds of the respondents consider that they spend more time on the Internet than required. The top motivation for college students to use the Internet is academic and career development. However, the application on which they spend the longest time is not academic resources websites but the instant messenger QQ. Even for a class that does not require an Internet access, more than $90 \%$ of the repliers will surf the Internet during the class time. High percentage of college students is not able to control their usage of the Internet well, which leading to their recognition that the Internet is a negative factor in their course performance. The findings in the paper are helpful for educators to guide students to use Internet in a reasonable way and to find ways to make the Internet to be beneficial to successful learning and high education quality.

\section{Acknowledgment}

The authors are grateful to the anonymous reviewers for their valuable comments and to the editors for their work that improved this paper. This work was supported by National Key Technology Research and Development Program of China under grant No.2014BAK14B04, NSF of Zhejiang under grant NO.LQ13F020017, LY14F020044, LY16F020018, and NSF of China under grant NO.61300211, 61572163, 61472112, J1524009.

\section{References}

[1] Deloitte, "Making the grade 2011: A study of the top 10 issues facing higher education institutions", Québec, Canada: Deloitte \& Touche, (2011).

[2] Ernst, Young (Firm), "University of the future: a thousand year old industry on the cusp of profound change", Sydney, New South Wales, (2012).

[3] K. L. Hui, S. L. Pan and B. Tan, "The Impact of Internet on Education: Towards an Emerging Paradigm", Pacific Asia Conference on Information Systems, (2010).

[4] I. Vogelsang and B. M. Compaine, "The Internet upheaval: raising questions, seeking answers in communications policy”, MIT Press, (2000), pp. 71-71.

[5] Association N E, Washington, DC, "A Survey of Traditional and Distance Learning Higher Education Members", (2000).

[6] B. S. Jerrik, "Massive Open Online Course", Part Press, (2012).

[7] O. O. Course, O. C. Platform and V. Scarani, "Free online courses from NUS on Coursera", Chronicle of Higher Education, (2014).

[8] R. A. Stewart, A. Walker and K. Panuwatwanich, "Students acknowledge that deep assessment types improve engineering graduate attributes: Shallow learning still prevails", Aaee Conference, (2012).

[9] E. J. Lee, "A case study of Internet Game Addiction", Journal of Addictions Nursing, vol. 22, no. 4, (2012), pp. 208-213.

[10] X. Zhang, "Investigation and aanlysis of zhai lifestyle's effects on college students' physical and mental health", World Journal of Education, vol. 3, no.4, (2014), pp. 26-34.

\section{Authors}

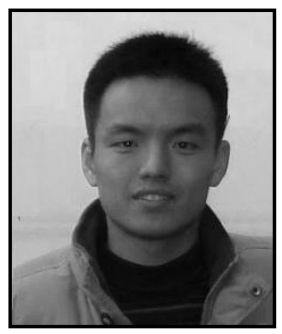

Renjie Zhou, is an assistant professor in School of Computer Science and Technology at Hangzhou Dianzi University, Hangzhou, China. He received his Ph.D. degree from Harbin Engineering University, Harbin, China, in 2012. He was a visiting scholar in the Department of Electrical and Computer Engineering at the University of Massachusetts at Amherst. Currently. His research interests include analysis of online social networks, and network security. 

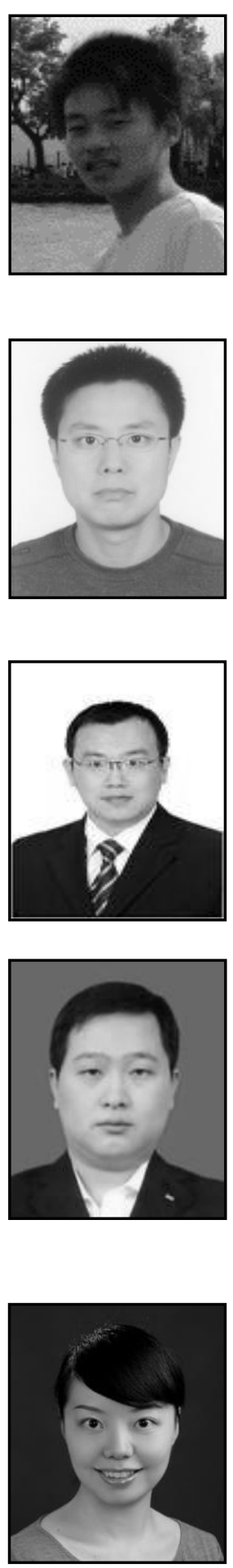

Dongchen Xia, He is a Master candidate in School of Com-puter Science and Technology at Hangzhou Dianzi University, Hangzhou, China. He is with the cloud computing research institute of Hangzhou Dianzi University. Before joining Hangzhou Dianzi University, he was a college student in Zhe-jiang Shuren University from 2010 to 2014. His current research areas is measurement and analysis of online social networks.

Yuyu Yin, received the Ph.D. degree in computer science from Zhejiang University, Zhejiang, China, in 2010. He is currently an Associate Professor with Hangzhou Dianzi University, Hangzhou, China. His research interests include service computing, cloud computing, and middleware techniques.

Jilin Zhang, received the $\mathrm{PhD}$ degree in Computer Applied Technology from University of Science Technology Beijing, Beijing, China, in 2009. He is currently an associate professor at Hangzhou Dianzi University, China. His research interests include High Performance Computing and Cloud Computing.

Wei Zhang, is an associate professor in School of Computer Science and Technology at HangzhouDianzi University, Hangzhou, China. He received the BE degree in School ofInformation Science and Engineering of Wuhan University of Science andTechnology in China in 2000, and he received the MEc and $\mathrm{PhD}$ degree in ComputerSchool of Wuhan University in China in 2004 and 2008, respectively. Hisresearch interests include network application and Intelligent Computing. He isa member of Association for Computing Machinery (ACM) and China ComputerFederation (CCF)

Jin Feng, is a lecturer of PLA the Rocket Force Command College. She gains Law Juris Master degree of Central China Normal University in 2013.Her research areas are Cyber Crimes and Cyber Security Law. 
International Journal of Security and Its Applications

Vol. 10, No. 6 (2016) 